\title{
MIRAGENS PERIMETRAIS: SOBRE O ERRO COMO LIMITE
}

Paulo Sérgio de Souza Jr.

Paulo Sérgio de Souza Jr. Psicanalista, tradutor, doutor em Linguística pela Unicamp e pós-doutorando em teoria literária pela UFRJ. Membro do Centro de Pesquisas Outrarte (IELUnicamp).
RESUMO: O erro linguístico tem sido diversamente abordado ao longo das diferentes tradições dos estudos da linguagem. O presente trabalho propõe, a partir da psicanálise, uma discussão a respeito de possíveis considerações e sobre o que o erro viola. Assim, pretendemos vislumbrar onde, na topologia da língua, o erro encontra a sua morada, bem como questionar se, de fato, ele estaria aí em posição de limite.

Palavras-chave: Erro, linguagem, língua, limite.

ABSTRACT: Perimetrical mirages: on error as a limit. Linguistic error has been approached differently throughout different traditions of language studies. This paper, based on psychoanalytical doctrine, proposes a discussion about some possible considerations and about what error violates. Thus we want to envision where in the topology of language indwells linguistic error, and question whether, in fact, it would be there in some boundary position.

Keywords: Error, language, limit.

\section{HÁ ERRO - UMA INTRODUÇÃO TÉTICA}

"nunca cometo o mesmo erro

duas vezes

já cometo duas três

quatro cinco seis

até esse erro aprender

que só o erro tem vez."

(Paulo Leminski, La vie en close, p.60)

“Errar é humano”, diz a máxima. E, ao falarmos de erro, certamente seremos impelidos a dizer de sua constituição como um processo não subestimável, sobretudo na medida em que 
histórico: é a historicidade do erro - uma vez que ele promove sempre uma diferença, seja por meio de uma descontinuidade entre o que o precede e aquilo que o sucede; ou, ainda, uma continuidade que impede a circunscrição de um domínio isolado - que constitui a certeza de sua própria garantia como algo que tenha efeitos na superfície do discurso. E é esse viés histórico que corrobora sua filiação, pois, ao âmbito das práticas humanas.

A história, por sua vez, entendida como algo que se constitui no próprio trânsito entre a pura língua e o discurso, ${ }^{1}$ é possibilitada exatamente pela diferença de potencial em jogo nessa passagem. ${ }^{2} \mathrm{E}$, nessa correlação, somos também obrigados a situar a raiz do erro para além da própria noção de história, como presente já no vetor que parte do semiótico rumando ao semântico, visto que a língua mesma, em sua “ordem própria” (SAUSSURE, 1916/1972, p.31), interdita que tudo se possa dizer. Isso significa que, uma vez dispostos a perscrutar o que caracteriza a condição humana enquanto tal — visto que "a linguagem ensina a própria definição do homem” (HUMBOLDT apud AGAMBEN, 1978/2005, p.60) —, podemos dizer, de saída, que "errar é linguístico".

No que concerne ao erro de língua, discute-se com frequência a respeito de qual estatuto aquele tem nesta; e pode-se notar, no trato da linguagem, como é que o erro tem sido diversamente processado ao longo das diferentes tradições. Contudo, os questionamentos que advêm não saberiam abalá-lo em sua existência como tal: depreende-se que o erro há e que ele permeia as práticas linguísticas mais irrisórias, uma vez que, ainda que tomemos o falante exclusivamente em sua condição de falante - isto é, como alguém detentor apenas de um conhecimento epilinguístico ${ }^{3}$ sobre sua língua —-, somos obrigados a reconhecer que ele, por via de um estranhamento, é sempre capaz de identificar algo passível de ser nomeado como sendo um erro de língua, sem que com isso, muitas das vezes, consiga precisar o que aí lhe estranha, ou mesmo fazer com que outro

\footnotetext{
1 "Somente porque [...] há uma diferença entre língua e discurso, entre semiótico e semântico, somente por isso existe história, somente por isto o homem é um ser histórico" (AGAMBEN, 1978/2005, p.64).

2 "É, com efeito, a diferença que talha a cesura do isolamento na homogeneidade da linguagem e que, inversamente, abre em cada sistema as vias para um outro. A instabilidade interna dos ciclos e o equívoco de suas relações não são dois problemas. Sob essas duas formas, como relação com o outro e como relação consigo, um confrontamento incessante trabalha a história, legível nas rupturas que fazem os sistemas bascularem e nas coerências que tendem a recalcar uma alteração interna. Há continuidade e descontinuidade, todas as duas enganadoras, porque nesse 'modo de ser da ordem' que lhe é própria, cada momento epistemológico carrega em si uma alteridade que toda representação procura eliminar objetivando, mas sem jamais poder sufocar seu obscuro trabalho e nem prevenir seu veneno mortal” (DE CERTEAU, 2002, p.168; tradução livre).

3 Termo utilizado por Culioli (1968) para designar o saber inconsciente que todo falante possui sobre sua própria língua - anterior, portanto, a uma metalinguagem, a um aparato que possibilite construir um saber objetivo sobre essa língua.
} 
sinta ali o mesmo e compartilhe do seu estranhamento; em algumas ocasiões, aliás, ele sequer pode oferecer àquilo que causa tal sensação uma alternativa que a reconforte.

Mesmo que possamos dizer, minimamente orientados pela noção de níveis de análise (BENVENISTE, 1964), que, nesse processo de aperceber-se dele, o erro apresenta diferentes nuances - afinal, ninguém contrariaria a afirmação, mesmo que razoavelmente obscura, de que há diferença quanto ao estatuto do erro ao se ponderar as equivalências, por exemplo, entre uma troca de letras numa palavra e uma violação de uma regra sintática —-, iniciaremos o presente trabalho com uma discussão situada num ponto um pouco aquém dessas nuances, isto é, por meio da seguinte pergunta: o que é que o erro, como tal, viola? Assim, poderemos nos guiar conforme nossos propósitos, tornando-nos capazes de vislumbrar onde, na topologia da língua, o erro encontra o seu abrigo; e questionar se, de fato, ele se encontra em posição de limite, visto que, ao nos darmos conta de que a língua não vai em todos os sentidos — isto é, que "não se diz tudo" (MILNER, 1978/2012, p.69) —, talvez fôssemos levados a crer que um dos papéis do erro fosse justamente o de estabelecer os seus lindes.

\section{A LUPA DA LETRA: O ERRO ATRAVÉS}

"Sem o escrito não há nenhuma forma possível de chegar a questionar o que resulta essencialmente do efeito da linguagem como tal."

(Jacques Lacan, 17 de fevereiro de 1971)

Longe de se pretender reduzir o erro a uma palavra-mestra, ainda assim parece inevitável situá-lo sob os auspícios daquilo que o evidencia, a saber, a escrita — na medida em que, sabe-se, é apenas a partir do seu estabelecimento que determinado saber consistente sobre a língua se torna possível (AUROUX, 1992, p.22).

Sabe-se que, por um lado, “a escrita obscurece a visão da língua” e "não é um traje, mas um disfarce” (SAUSSURE, 1916/1972, p.40) - que se lembre aqui, é necessário dizer, da potência do efeito de báscula promovido pelo gesto saussuriano, que coloca a língua falada à frente da escrita em termos de privilégio de estudo; por outro, contudo, caso pensemos no processo de reflexão sobre a língua atual frente aos estados anteriores, já somos obrigados a reconhecer que a escrita tem aí um papel de esclarecimento fundamental.

Além do mais, por meio de sua fixidez, ela garante a leitura de textos de outras épocas com os quais muitas vezes não se teve contato prévio — ou com o escrito em si, propriamente, ou com o texto oral que lhe deu origem. Ainda, como prótese mnêmica, é capaz de livrar da necessidade do conhecimento, de cor, dos textos que se deseja fazer uso. Assim, ela vai subitamente na contramão 
da própria imutabilidade, uma vez que sua fixidez também denuncia, para além da variação sincrônica à qual o falante tem acesso, o efeito da diacronia pesando sobre a língua. Mas não só, já que chega, como Saussure mesmo é obrigado a reconhecer, a causar modificações no próprio estado de língua que lhe é contemporâneo: o que vai ser nomeado no Curso como uma espécie de auge da "tirania da letra”, quando a escrita acaba por influir na língua, modificando-a (idem, p.41).

Essa dimensão da variação que a escrita submete aos sentidos do falante não deixa de ter efeitos, visto que a variação linguística, sincrônica ou diacrônica, costuma ser encarada com maus olhos nas mais diversas tradições - em que vigoram considerações que datam de muito antigamente, por exemplo, como a de que a língua de um outro povo é uma língua menor, não sagrada; ou, ainda, a de que a capacidade de falar todas as línguas havia sido concedida ao primeiro dos homens, mas foi mais tarde perdida devido a algum infortúnio/intemperança: o orgulho humano e a insolência contra os seus deuses ocupam, para vários povos, esse lugar (tal qual se mostram justificativas, por exemplo, para a separação/perda que está em jogo na origem do amor, como no mito descrito por Aristófanes, conforme $\mathrm{O}$ banquete, de Platão).

A dimensão do sagrado como estando atrelada aos fenômenos linguísticos se mostra, desde então, no cerne de muitas das concepções tanto sobre a origem da linguagem - e.g. o povo dogom (AUROUX, 1992, p.19) —, quanto sobre a diversidade das línguas - e.g. o mito babélico; o mito da confusão das línguas por Zeus, para os gregos. E o sagrado, aliás, chega a garantir o seu lugar de tangência inclusive em produções gramaticais mais recentes - e.g. a querela entre jesuítas e jansenistas no século XVII (DEFIZE, 1988).

Os primeiros relatos de estudos gramaticais já haviam colocado em cena a religião. Tomemos a Índia politeísta do século IV a.C.: é nesse período que encontramos a gramática de Panini e, já aí, a frutífera noção de boa formação — de palavras, até então — ${ }^{4}$ que estava em jogo na língua que se acreditava que, aos poucos, vinha se perdendo devido à variação. Essa língua, com a qual o gramático trabalhou em sua Ashtadhyayi, ${ }^{5}$ é aquela em que foram escritos os Vedas; e o objetivo de sua compilação de regras guarda relação íntima com o fato de que os eruditos acreditavam que o sânscrito, considerado a língua dos deuses, estava sofrendo mudanças e se degradando, o que poderia acarretar severas implicações

\footnotetext{
${ }^{4}$ A palavra como unidade privilegiada atravessará grande parte do período clássico, como na obra de Dionísio, o Trácio - autor, no século II a.C., da primeira gramática ocidental documentada. A frase só começará a ser tomada como unidade de análise no século II d.C., com Apolônio Díscolo e seus trabalhos sobre a sintaxe do grego.

${ }^{5}$ A gramática de Panini é composta por aproximadamente 4 mil regras, além de alguns anexos - como uma lista de aproximadamente 2 mil raízes. Foi tão profícua que até hoje ainda desperta grande interesse, como denuncia um projeto (Grammaires Paninéennes) em curso, no momento, dedicado exclusivamente ao seu estudo no Instituto Francês de Pondichéry.
} 
religiosas: uma diferença/erro aparentemente banal de pronúncia, por exemplo, seria capaz de colocar toda uma cerimônia a perder.

Vemos, então, uma estreita relação entre mudança e erro, isto é, entre a noção seminal de erro, nos primórdios da gramática, e a violação de uma língua anterior - correlata a um momento mítico (muitas vezes sagrado) de pureza - à qual deveríamos nos reportar sempre, por algum motivo, e por cuja preservação deveríamos supostamente zelar: refreando a mudança; retornando aos primórdios desse gozo perdido que estaria em jogo para uma língua imaculada; recusando a falta, na busca de uma língua de fato completa.

Tal entendimento que afirma a língua atual como algo que violaria um estado anterior estará por detrás da própria noção de erro gramatical — e, se não estivesse, correríamos o risco do anacronismo, visto que a violação pressupõe algo que já havia para, então, num segundo tempo, ser violado —, o que, ao se replicar, supõe a remissão a uma espécie de idioma “pré-babélico”, que figuraria como língua ideal. Basculando dessa língua ideal ao ideal de língua, vemos que se identifica no erro certa natureza transcendente, ${ }^{6}$ pois, apesar de exceder toda e qualquer língua, manifesta-se em cada uma: o erro quotidiano viola a língua no estado atual; a variante regional viola o standard; o erro que se torna fato de língua viola o estado de língua anterior; o idioma como tal viola a língua que lhe deu origem.

Não será diferente, portanto, nas tradições dos séculos seguintes, como se pode ver com o segundo período da história da Linguística, conforme descreve o Curso de Ferdinand de Saussure (1916/1972, p.7): a Filologia. Apesar de haver aí uma preocupação maior com outras questões - datação, interpretação e comentário de textos clássicos — - ela acaba por estabelecer, ainda que por outras vias, a mesma suposição de primazia à língua dos antigos: o próprio Saussure aponta como uma falha da disciplina a atenção exclusiva a textos escritos (literários, além do mais, lembremos), em detrimento do atual da língua falada, que vai ser entendida como uma manifestação linguística menor (idem, p.8). O erro, portanto, reconhece o seu lugar para além da língua, isto é, no descompasso entre a língua atual e o lugar fantasístico que a imagem de uma língua perdida guarda para si — descompasso que guiará a noção de norma que acompanha, com fertilidade, a tradição gramatical no âmbito escolar até mesmo nos dias de hoje. ${ }^{7}$

\footnotetext{
${ }^{6}$ Damos a medida desse termo conforme a lógica medieval entende os transcendentia, isto é, predicados que transcendem as categorias, mas persistem em todas elas (AGAMBEN, 1978/2005, p.13).

${ }^{7}$ Nas gramáticas escolares - seja de primeira língua, seja para aprendizado de língua estrangeira - o trabalho gramatical normativo, entendido como arte, faz do erro a violação de uma tekhné consolidada pelas mãos de grandes escritores, deixando ao sabor do cânone - e daquilo que o garante enquanto tal, então — os poderes de fixar seus lineamentos: a boa língua; a língua dos doutos; a língua das pessoas de bem; a língua dos bons costumes.
} 
Se pensarmos em Port-Royal, por sua vez, a questão encontra o seu reverso. Aqui, a noção de gramática rompe com a tradição que vê sua exímia figuração no trabalho de Vaugelas (Remarques sur la Langue Française, 1647), isto é, ela não será entendida como uma teoria dos usos, e sim como uma disciplina que incide sobre a própria racionalidade e generalidade que estão em jogo na função da linguagem compartilhada pelos homens. ${ }^{8}$ Visto que a língua, no caso, é tomada como uma expressão daquilo que se pensa, o erro de língua consiste em erro de pensamento: a língua se isenta do erro, isto é, o erro em si encontra-se aquém da língua.

Ao nos ampararmos no próprio Curso saussuriano, caso caminhemos um bocado mais adiante na história das reflexões linguísticas, vemos que a questão parece se espelhar outra vez. Afinal, se é "a fala que faz evoluir a língua" (SAUSSURE, 1916/1972, p.27) e, ao mesmo tempo, se "as inovações da fala não têm [todas] o mesmo êxito e, enquanto permanecem individuais, [para a Linguística] não há porque levá-las em conta” (idem, p.115), depreendemos que o movimento individual, num primeiro momento - enquanto fato de fala —, nada mais é do que erro frente ao fato de língua do qual ele se desvia, isto é, novamente se presentifica a violação de uma cristalização e o erro retoma o seu lugar de além-da-língua.

Mas e hoje? Bem, se podemos dizer do erro no atual estado da arte vemos que a gramática gerativa — em seu lugar privilegiado entre as abordagens atuais do fenômeno da linguagem — trata-o de maneira a tornar evidente uma relação necessária para pensá-lo de forma profícua para o campo da psicanálise. É o que veremos mais adiante.

\section{DOIS ERRES DO ERRO}

A gramática gerativa, acreditamos, é a que melhor situa o erro em sua natureza bífida: 1) de um lado, temos a violação no sentido gramatical leigo, que, apesar de não ser valorado negativamente — já que a normatividade não é o que está para ela em jogo — , não deixa, contudo, de ser fundamental para os estudos que contrastam os funcionamentos das línguas entre si; 2) de outro, há o erro enquanto algo que o julgamento de gramaticalidade do falante é capaz de descartar (caracterizar como algo que não pertence à sua língua), e que só compareceria na fala por conta de uma falha de processamento.

\footnotetext{
8 "Primeiro que tudo, ela marca, intencionalmente pelo menos, o fim do privilégio reconhecido, nos séculos precedentes, à gramática latina, que tendia a apresentar-se como modelo para qualquer gramática: a gramática geral é tanto latina, quanto francesa ou alemã, mas transcende a todas as línguas" (DUCROT \& TODOROV, 1972/2001, p.220).
} 
Do segundo tipo supõe-se que ele pode ser discriminado por meio de um juízo enunciável pelo falante, e que a violação em que esse erro consiste, muitas vezes, de um princípio fundamental para a língua que lhe é materna, funciona como uma espécie de proibição que sequer precisa dizer seu nome através da gramática normativa. Podemos ver, nos dois exemplos do Português Brasileiro (PB) que se seguem, locuções que figuram bem aquilo que chamamos aqui de natureza bífida do erro:

1) Os menino saiu.

2) ${ }^{*}$ Menino o saiu.

A primeira sentença, considerada uma variante com relação ao português standard (“os meninos saíram”), não é condenável pela linguística como erro, mas não deixa de estar marcada com uma diferença, minimamente na medida em que conota, no sentido hjelmsleviano do termo (HJELMSLEV, 1943/1968). A segunda, por sua vez, é uma frase que não faz parte do conjunto dos enunciados possíveis em $\mathrm{PB}$, o que faz dela, nessa perspectiva, um erro que se poderia, no âmbito da disciplina, chamar de legítimo: uma má formação, de fato. Contudo há aí, para além de matizes, cores que se distanciam muito no espectro: nesses dois exemplos, onde é que se erra, com efeito? Façamos, então, certa disjunção para assediarmos o erro de um modo que nos parece fundamental.

Em 1), a violação consiste na ruptura com a formalidade da regra em sua vertente normativa, no que diz respeito à arte da gramática tradicional; porém, não se pode dizer - uma vez que se é imaginariamente capaz de dizer o que é uma língua - que essa frase não é do PB. Já em 2), a frase viola uma das constituintes básicas do PB, a saber, que os artigos sempre precedem os nomes. Quando essa regra é violada, o nível de estranhamento dirá respeito ao próprio reconhecimento de que o que ocorre ali é a intromissão de algo que, por meio de sua exclusão, antes se encontrava em posição de assegurar à língua a garantia de sua integridade. Com isso, a possibilidade de situar o PB como sendo uma língua, antes mesmo de ser uma língua entre outras, é pouco garantida pelo fato de que haja outras línguas que não são o PB — ainda que, com efeito, soe tentador acreditar que aquilo que faz o PB ser o PB é o fato de que ele não é o português europeu, o kamayurá ou o russo, por exemplo. Há aí um tempo anterior: o que está em jogo na constituição dessa língua como supostamente idêntica a ela mesma é a própria possibilidade de dizer, de dentro do PB, o que ele não é. ${ }^{9}$

\footnotetext{
9 Note-se, aí, a inevitável remissão à inconsistência da língua, e os meandros que, de fato, enlaçam o todo e o não-todo no que diz respeito aos estudos linguísticos (MILNER, 1978/2012, cap.5).
} 
Talvez possamos dizer, então, que em 1) ocorre uma violação do contingente, enquanto que em 2) ocorre uma violação no nível do necessário - e, nesse sentido, a segunda violação incide num dos pontos de estabilidade imprescindíveis à construção de uma fronteira imaginária entre o que é ou não é uma língua. Pode-se depreender, então, que o erro necessário promove a possibilidade de vislumbrar a língua enquanto toda: essas locuções, ao permanecerem num pretenso fora, são condição para podermos tomar a língua como um Todo idêntico a si mesmo - em outras palavras: pensá-la como um sistema, como forma.

A partir do que havia feito Jean-Claude Milner (1978/2012) — que fala da proibição na língua como uma encarnação do impossível do incesto - - e tendo em vista a disjunção que acabamos de fazer entre essas manifestações que chamamos de erro, somos compelidos a estabelecer uma distinção lá onde o autor estagnou a pena. O erro necessário seria, ele sim, o que podemos conceber como estando do lado daquilo que Milner (1978/2012, p.81) chama de "Édipo linguístico”. Mas e a proibição do erro contingente, por sua vez? Com o que estaria relacionada?

Acreditamos poder elucubrar que o erro do tipo 1) parece estar ligado mais a um desejo de não desejo, atuando como gestos em direção ao retorno ao gozo perdido da língua ideal. A possibilidade desse tipo de erro supõe uma regragem do dizer que, apesar de se manifestar justo pela coerção, está referenciada por outro tempo, um tempo sem lei - o que pode parecer contraintuitivo, mas mais compreensível se pensarmos naquilo que está em jogo para o supereu, que, segundo Lacan (1972-73/2008, p.11), é precisamente “o imperativo do gozo — Goza!”.

Nesse ponto se torna clara a escolha da primazia dada ao sincrônico pela Linguística moderna em sua procura por filiação à ordem das ciências, deixando de lado o acúmulo diacrônico, que curtocircuita passado e presente da língua. ${ }^{10}$ Isso porque, se pensamos na tradição gramatical, salta aos olhos o estatuto da gramática enquanto arte, na medida em que ela dá conta de uma verdade que a ciência da linguagem procura obliterar: a do preço pago, a perda - acarretada pela entrada na linguagem - que tem sua morada num tempo que é póstumo a si mesmo (inapreensível à cronologia, portanto, e que por isso suscita um tempo lógico); tempo encarnado nos mitos que encenam a origem da linguagem, em termos filogênicos, e na infância do sujeito, em termos ontogênicos, como nos mostra Giorgio Agamben (1978/2005).

Contudo, precisar essa bifurcação não muda o curso do argumento de Milner, pois ambas as facetas do erro nos colocam no caminho de que ele nos fala: sobre o fato de o erro ser constituído de língua, de estar na língua. Se uma locução

\footnotetext{
${ }^{10}$ Não nos esqueçamos de que "o centro de gravidade do sujeito é essa síntese presente do passado a que chamamos história” (LACAN, 1953-1954/1986, p.48).
} 
é, então, proibida, o é na medida em que poderia ser proferida, tanto que a escrevemos aqui e, então, a notamos como incorreta; ou seja, o componente de impossibilidade em jogo na sua não execução não se deve a uma suposta suspensão do funcionamento linguístico enquanto tal.

\section{O VÉU E A VERGONHA: AUFHEBUNG E PUDOR}

“'Lalíngua', qualquer que seja, é uma obscenidade."

(Jacques Lacan, 19 de abril de 1977)

Uma vez, então, que o erro está na língua, e não se encontra em posição limítrofe entre o linguístico e o que não o seria, a necessidade de lidar com ele está posta para os falasseres (parlêtres); e, além do mais, pode-se notar que estes operam com ele: colocam óleo em suas juntas para seguir adiante. O erro, visto que é língua, não teria mesmo como estancar a operação significante.

Se, todavia, como nos aponta Milner, a língua é uma rede recoberta por falhas, isso não quer dizer que essas falhas constituam um Todo, ou seja, que se mostrem circunscritíveis e possam solidamente se agregar em seu lugar de excrescência; muito pelo contrário, essas falhas desenham um não-todo - "lalíngua é não-toda” (MILNER, 1978/2012, p.39).

A Linguística, contudo - e para isso se ampara inclusive no erro que aqui chamamos de necessário - , imaginariza uma agregação para esses pontos de equívoco (que são frutos de determinado resultado do juízo de atribuição do falante a respeito de sua própria língua, e suscitam, no só-depois: ou uma rejeição da coisa que estava em causa, ou o seu desconhecimento acompanhado pela incapacidade de decidir a respeito dela), colocando-os numa posição de limite e, então, procurando assegurar o todo de seu objeto, quer lançando-os para a órbita das particularidades da fala, quer para a opacidade misteriosa do uso. Não se pode compreender mal, todavia: limite, aqui, não significa exterioridade, mas sim certa impossibilidade — apesar de se poder dizer a locução proibida, não se pode dizer dela.

Mas, no caso do erro contingente, há uma especificidade capital: pode-se dizê-lo, e também se pode dizer dele. ${ }^{11}$ Há alguma coisa em jogo aí que não é da

\footnotetext{
${ }^{11}$ No caso do erro necessário, não se pode conjeturar por que é que, no que diz respeito à própria língua, não se pode dizer "menino o", tampouco por que é que se diz, suponhamos, num determinando momento - pois, via de regra, esse enunciado sequer é dito. No caso do contingente, todavia, pode-se argumentar que "os menino saiu" é fruto da violação de uma lei explícita quanto à concordância, e arriscar algum motivo para tanto: uso de um registro informal ou pouca familiaridade com a norma culta, por exemplo; pode-se até chegar a dizer que o falante não conhece sobre a língua. Já no caso do erro necessário não podemos dizer o mesmo - salvo, obviamente, se se tratar de um falante estrangeiro (quem sabe um
} 
ordem do impossível: a possibilidade de algo que se relaciona com aquilo pelo qual nos referenciamos surdamente acima ao falarmos do aspecto religioso dos estudos da linguagem desde os seus primórdios: o erro viola.

Há uma dimensão do obsceno no que diz respeito ao erro; e com o obsceno, ora, sempre se soube o que fazer! Digamos que ele pode ser assediado de uma forma simples, mas não negligenciável: uma maneira corrente de encapsular o seu efeito é, no texto, o uso das aspas, uma vez que "a palavra entre aspas está suspensa em sua história” (AGAMBEN, 1985/1998, p.91).

Quando se pretende fazer com que algo de errado compareça no texto, as aspas parecem constituir um possível invólucro para que essa violação entre aí inócua ${ }^{12}$ - de tal modo que se possa operar e fazer com ela, já que o fato transgressor foi abarcado, circunscrito por esses sinais gráficos: as guillemets (aspas) abrem espaço para submergir os guille-mots (mergulhões/palavras) do pensamento: "lá onde falhou uma voz, onde faltou um sopro, um pequeno signo foi suspenso no ar. Sem outro suporte que não este, hesitante, o pensamento se aventura"13 (AGAMBEN, 1985/1998, p.93).

Além disso, se, conforme Lacan, pensamos o obsceno em sua conjuminação com a Outra cena — isto é, o anderobsceno de que ele fala em seu Seminário 24 (1976-77) — , também não deixamos de ver, aqui, a marca de um lugar ambíguo com relação à locução que as aspas abrigam, uma vez que, conforme a tradição da escrita de textos (sobretudo a acadêmica) consolidou, elas denotam que as palavras que ficam à sua sombra têm origem no discurso originado n'outro lugar; e essa intromissão se deixa ver com facilidade em língua alemã, que nomeia as aspas como Anführungszeichen, em que — por que não? — poderíamos ver precisamente as marcas de uma introjeção, Einführungszeichen.

\footnotetext{
falante de dinamarquês ou romeno aprendendo português possa vir a dizer "menino o" por assimilação de uma regra de sua própria língua, que posiciona o artigo definido como sufixo) - , já que o que está em jogo não é um saber sobre a língua, mas precisamente saber lalíngua. Sobre "saber a" e "saber sobre", cf. De Lemos (1991).

${ }^{12}$ Evidentemente, se o erro é trazido, e não traz a si próprio - como num lapso ou num chiste, por exemplo (FREUD, 1901/1905) —, essa estabilização já está de algum modo posta; mas é curioso que, em termos de efeito, as aspas sirvam exatamente para que um outro, o leitor, tome conhecimento de que aquele erro não constitui um lapso, mas sim algo que é da ordem da vontade do sujeito que escreve.

13 Nesse sentido, é interessante poder articular a garantia de certo desempenho do pensamento pela suspensão do recalque (Aufhebung der Verdrängung) possibilitada pela denegação, como mostra Freud em seu artigo sobre a Verneinung (1925): "Vermittels des Verneinungssymbols macht sich das Denken von den Einschränkungen der Verdrängung frei und bereichert sich um Inhalte, deren es für seine Leistung nicht entbehren kann." [Por intermédio do símbolo da negação, o pensar se livra das limitações do recalque e se enriquece com conteúdos dos quais não pode abrir mão para o seu desempenho].
} 


\section{REFLEXÕES FINAIS}

"Não apenas a inteira faculdade do pensamento reside na linguagem, [...] mas a linguagem é também o ponto central do mal-entendido da razão consigo mesma."

(Johann Georg Hamann, Sämtlichen Werken, v.III)

Se o erro, no sentido lato, não garante exterioridade propriamente dita, de onde viria essa sua pregnância quanto à construção de um limite como algo que é capaz de situar os alcances da língua?

Bem, para isso precisamos recorrer a um ato: ao "ato de violência" que consiste no par ordenado nas matemáticas, e do qual Lacan tira muitas consequências em seu seminário De um Outro ao outro (LACAN, 1968-1969/2008, p.74, 81), por meios dos diagramas de Euler, para pensar os conjuntos-objetos.

Para termos uma apreensão mais apurada da natureza do erro tal como vem sendo pensado neste trabalho, consideremos: sendo E o conjunto que representa o erro, e L, a língua, digamos que E é o subconjunto de L formado pelos elementos que não contêm a si mesmos - isto é, para $x$ ser elemento de $E$, $x$ não deve pertencer a $x$, e deve, simultaneamente, pertencer a L. Desse modo, a pergunta que podemos fazer é: E, enquanto elemento, pertence a si mesmo? Se assim fosse, transgrediria a regra de construção que, de início, determinamos para ele próprio. Contudo, se não o fosse, seria um conjunto que não contém a si, e deveria, pois, estar contido em E: o que nada mais é que o paradoxo de Russell. Mas se os elementos de E devem simultaneamente pertencer a L, uma vez que E é subconjunto de L, temos a seguinte configuração possível, à direita — em correspondência com o desenho, à esquerda, feito por Lacan no Seminário citado:

A

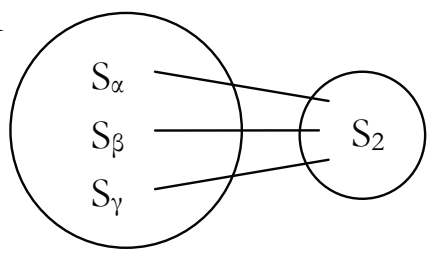

$\mathrm{L}$

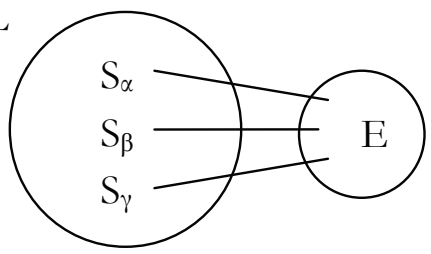

Vemos, assim, que, apesar de seus elementos estarem na língua, o erro como tal permanece fora dela - assim como o saber $\left(\mathrm{S}_{2}\right)$ se encontra fora do Outro (A), muito embora os significantes que o constituem façam, com efeito, parte do Outro - do "tesouro dos significantes", como nomeava Lacan.

O erro constitui, então, não um limite da língua, já que não poderíamos recorrer a uma topologia orientável para situar o seu lugar. Com efeito, o que há aí é uma espécie de limite interno, um fora-dentro simultâneo que suscita recorrer a formas de mostração de outra ordem. Se quisermos, de fato, apreen- 
der algo do erro que não se reduza a uma planificação balizada pela geometria euclidiana, pensemos, então, na figura de um oito-interior - que marca o percurso ao longo de uma banda de Moebius projetado sobre uma superfície:

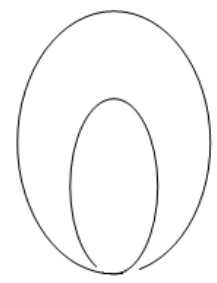

A morada do erro, então, possibilita, com efeito, a construção de um limite imaginário, um perímetro miraginal que descreve uma espécie de falso miolo — sem, no entanto, que a língua o deixe de fora, já que ele é interno a ela. É essa possibilidade de ver o descompasso que constitui o erro com relação à língua que faz com que ele possa ser situado como o representante cabal da remissão significante-significante — o erro, antes de mais nada, supõe a remissão a outro significante.

Além disso, o erro faz ressoar a própria dissonância entre o simbólico e o real: ele é aquilo que, na língua, dá a ver a possibilidade da estrutura, fazendo com que reconheçamos aí a afirmação explícita que faz Lacan (1964/1985, p.27), ao pronunciar que só daquilo que falha é que há causa; ou, o que ainda pode nos dizer a literatura, na pena de um Duhamel (1949, p.27): “o erro é a regra. A verdade é o acidente do erro" que a letra vem grafar, poderíamos acrescer. Mas se a escrita possui, feito Janus, suas duas caras - como já pudemos notar ao discutirmos sobre a importância da letra para os estudos linguísticos —, embora também se possa, por meio dela, abrandar o erro, procurando esvair as suas forças, por exemplo, por meio do emprego dos singelos sinaizinhos gráficos que compõem as aspas, "no momento em que ela [a palavra] parece se esvaziar de toda significação e dar o último suspiro, os pequenos algozes, saciados porém inquietos, retornam à vírgula que é sua origem e que, segundo Isidoro de Sevilha, marca o ritmo da respiração na formulação do sentido" (AGAMBEN, 1985/1998, p.93).

O itinerário significante, então, prossegue apontando-nos — reféns da língua que nos falta e da inconsistência do Outro - a brecha em que se fixa a oportunidade da demanda: ${ }^{14}$ entre as duas revelações da esfinge, cada qual com a sua porção do erro. De um lado, a mãe como objeto sexual e o erro que viola no

14 “É na medida em que o campo do Outro não é consistente que a enunciação assume a feição da demanda, e isso antes mesmo que aí se venha instalar seja o que for que carnalmente possa responder a ela" (LACAN, 1968-1969/2008, p.82). 
nível do necessário; de outro, o assassinato do pai, e o erro que viola no nível do contingente - marcado pela norma, por um supereu linguístico que ecoa como as vozes da consciência de que havia falado Freud em Totem e tabu.

Recebido em 5/3/2012. Aprovado em 30/4/2012.

\section{REFERÊNCIAS}

AGAMBEN, G. (1978/2005) “Infância e história”, in Infância $e$ história. Trad. de Henrique Burigo. Belo Horizonte: UFMG.

(1985/1998) Idée de la prose. Trad. de Gérard Macé. Paris: Christian Bourgois Éditeur.

AUROUX, S. (1992) A revolução tecnológica da gramatização. Trad. de Eni Orlandi. Campinas: Ed. da Unicamp.

BENVENISTE, E. (1964/1988) “Os níveis de análise linguística”, in Problemas de linguística geral I. Trad. de Maria da Glória Novak e Maria Luiza Neri. Campinas: Pontes e Editora da Unicamp.

CULIOLI, A. (1968) La formalisation en linguistique. Cahiers pour l'analyse, n.9, p.106-117.

DE CERTEAU, M. (2002) “Le noir soleil du langage: Michel Foucault”, in_. Histoire et psychanalyse. Paris: Gallimard.

DEFIZE, T. (1988) Comment confondre les jensenistes?, Histoire, épistémologie, langage, X(1), p.43-58.

DE LEMOS, C. Th. G. (1991) Saber a língua e o saber da língua. Aula inaugural dada no Instituto de Estudos da Linguagem - IEL/Unicamp. Publicação interna, Campinas.

DUCROT, O. \& TODOROV, T. (1972/2001) Dicionário enciclopédico das ciências da linguagem. São Paulo: Perspectiva.

DUHAMEL, G. (1949) Chronique des Pasquier, I. Paris: Mercure de France.

FREUD, S. (1979) Obras completas. Buenos Aires: Amorrortu.

(1901) "Psicopatología de la vida cotidiana”, v.VI. p.1-306

(1905) “El chiste y su relación con el inconsciente”, v.VIII, p.1-247.

HAMANN, J. G. (1949-1957/1999) Sämtliche Werken. Wuppertal: Brockhaus. HJELMSLEV, L. (1943/1968) Prolegomènes à une théorie du langage. Paris: Minuit. LACAN, J. (1953-1954/1986) O seminário livro 1, Os escritos técnicos de Freud. Trad. Betty Milan. Rio de Janeiro: Jorge Zahar. (1964/1985) O seminário livro 11, Os quatro conceitos fundamentais da psicanálise. Trad. de M. D. Magno. Rio de Janeiro: Jorge Zahar. (1968-1969/2008) O seminário livro 16, De um Outro ao outro. Trad. de Vera Ribeiro. Rio de Janeiro: Jorge Zahar. (1970-1971/2006) Le séminaire livre 18, D’un discours qui ne serait pas du semblant. Paris: Seuil. 
(1972-1973/2008) O Seminário livro 20, Mais, ainda. Trad. de M. D. Magno. Rio de Janeiro: Jorge Zahar.

(1976-1977) Le séminaire livre 24, L’insu que sait de l'une bévue s’aile à mourre. [inédito].

LEMINSKI, P. (1991) La vie en close. São Paulo: Brasiliense.

MILNER, J.-C. (1978) O amor da língua. Trad. de P. S. de Souza Jr. Campinas: Editora da Unicamp.

SAUSSURE, F. (1916/1972) Curso de linguística geral. Trad. A. Chelini, J. P. Paes, I. Blikstein. São Paulo: Cultrix.

Paulo Sérgio de Souza Jr. zlatic.jr@gmail.com 